\title{
KLHS untuk Pembangunan Daerah yang Berkelanjutan
}

\author{
Widodo B. ${ }^{1}$; Ribut L. ${ }^{2}$; Donan W. ${ }^{2}$ \\ ${ }^{1}$ Jurusan Teknik Lingkungan FTSP UII/ DPPM UII \\ e-mail: widodo indo@yahoo.com, HP 0818.0421.3321 \\ ${ }^{2}$ Pusat Studi Lingkungan (PSL) UII
}

\begin{abstract}
Abstrak
Pilar utama pembangunan adalah aspek ekonomi, sosial, dan lingkungan. Keberhasilan pembangunan selain dicirikan oleh peningkatan pertumbuhan dan pemerataan kesejahteraan, juga mesti ada jaminan keberlanjutan. Untuk konteks Indonesia, pengarustamaan pembangunan berkelanjutan telah ditetapkan sebagai landasan operasional pembangunan, sebagaimana tercantum dalam RPJP dan RPJM Nasional dan Rencana Tata Ruangnya. Setiap proses perencanaan sampai dengan pelaksanaan pembangunan diharuskan mengandung kepentingan pelestarian lingkungan hidup. Perhatian terhadap pelestarian lingkungan hidup idealnya sudah muncul dan ditempatkan sejak proses awal perumusan strategi hingga pelaksanaan pembangunan. Konsekuensi dari tuntutan ini adalah hadirnya instrument pengkajian terhadap lingkungan hidup pada tataran strategis setara dengan strategi pembangunan itu sendiri. Paper ini menguraikan sekilas tentang metode baru untuk mengkaji lingkungan hidup yang disebut Kajian Lingkungan Hidup Strategis (KLHS) dan contoh hasil analisis KLHS di Kartamantul.
\end{abstract}

Kata Kunci: KLHS, pembangunan daerah berkelanjutan, Kartamantul, Yogyakarta

\section{Konsepsi KLHS}

Sejak tahun 1990-an di dunia internasional telah berkembang Kajian Lingkungan Hidup Strategis (KLHS) atau Strategic Environmental Assessment (SEA). KLHS merupakan penyempurnaan dari AMDAL sebagai instrument lingkungan hidup yang sudah ada sebelumnya. Jika AMDAL hanya hadir pada tingkat proyek, maka KLHS ada pada Kebijakan, Rencana, dan atau Program (KRP) pembangunan.

Kementerian Negara Lingkungan Hidup (2007) memberikan definisi KLHS yang dipandang sesuai untuk Indonesia dengan memperhatikan kondisi sumberdaya alam, lingkungan hidup, sosial, ekonomi, politik, serta kapasitas SDM dan institusi di masa mendatang, yaitu:

"Suatu proses sistematis untuk mengevaluasi pengaruh lingkungan dan menjamin diintegrasikannya prinsip-prinsip keberlanjutan dalam pengambilan keputusan yang bersifat strategis".

Definisi dan praktek KLHS di dunia selama ini mengindikasikan terdapat dua basis pendekatan KLHS, yaitu KLHS dengan basis pendekatan AMDAL (EIA-based SEA) dan dengan basis pendekatan keberlanjutan (sustainability-led SEA). KLHS dengan basis pendekatan AMDAL mengkaji lebih dari sekadar level proyek yakni hingga evaluasi konsekuensi positif dan negative dari kebijakan, rencana, dan program. KLHS dengan basis pendekatan keberlanjutan 
memformulasikan visi, tujuan, dan kerangka kerja keberlanjutan untuk memandu pengambilan keputusan KRP yang lebih baik, sehingga harus mengintegrasikan aspek sosial, ekonomi, dan biofisik dalam proses KRP (DEAT, 2004). KLHS dengan basis pendekatan keberlanjutan ini telah berkembang menjadi KLHS untuk jaminan keberlanjutan lingkungan hidup (SEA for environmental sustainability assurance, ESA).

Aplikasi KLHS dilaksanakan di sepanjang proses KRP. Pada level kebijakan dapat diaplikasikan KLHS Kebijakan, pada level rencana dan program dapat berupa KLHS Regional (termasuk tata ruang), KLHS Program, dan KLHS Sektor. Pada Gambar 1 adalah gambar skematis yang menunjukkan lingkup aplikasi KLHS dan yang membedakan dengan AMDAL.

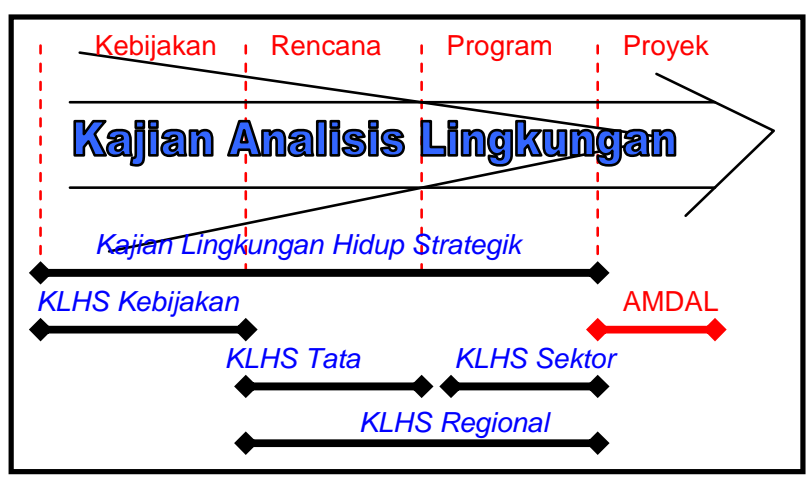

Gambar 1. Lingkup Aplikasi KLHS (Partidario, 2000)

Menurut The International Association of Impact Assessment (IAIA, 2002), KLHS berkualifikasi tinggi bila mampu menginformasikan hal:

a. Keputusan strategik yang tengah diformulasikan (dimana keputusan tersebut mengadopsi prinsip keberlanjutan).

b. Kemampuan mendorong munculnya alternatif penghidupan yang lebih baik.

c. Jaminan KLHS berlangsung demokratis.

Tujuan KLHS hakikatnya adalah lahirnya kebijakan, rencana, dan program yang melalui proses partisipasi, transparan, dan akuntabel dengan memperhatikan aspek lingkungan hidup dan keberlanjutan. Hal ini tercermin dalam prinsip-prinsip KLHS sebagaimana diletakkan oleh Sadler dan Verheem (1996) serta Sadler dan Brook (1998) antara lain:

- Sesuai kebutuhan (fit-for the purpose)

- Berorientasi pada tujuan (objectives led)

- Bermotif keberlanjutan (sustainability driven)

- Lingkupnya komprehensif (comprehensive scope)

- Relevan dengan kebijakan (decision relevant) 
- Terpadu (integrated)

- Transparan (transparent)

- Partisipatif (participative)

- Akuntabel (accountable)

- Efektif biaya (cost effective)

Untuk lingkup Indonesia, KLH (2007) memformulasikan 3 nilai yang penting untuk dianut dalam aplikasi KLHS, yaitu:

1. Keterkaitan (interdependency)

Penyelenggaraan KLHS harus mempertimbangkan keterkaitan antara satu komponen dengan komponen lain, antara satu unsur dengan unsur lain, antara lokal dan global, antar sektor, antar daerah, dan sebagainya. Atau dengan kata lain KLHS diaplikasikan secara komprehensif dan holistik.

2. Keseimbangan (equilibrium)

KLHS harus senantiasa dijiwai oleh nilai-nilai keseimbangan, seperti keseimbangan kepentingan sosial ekonomi dengan lingkungan hidup, keseimbangan kepentingan jangka panjang dan jangka pendek, keseimbangan pusat- daerah, dan lainnya.

3. Keadilan (justice)

Nilai keadilan akan membatasi akses dan kontrol terhadap sumberdaya alam atau modal atau pengetahuan, sehingga hasil KLHS berupa kebijakan, rencana, dan program tidak menyebabkan marginalisasi kelompok masyarakat tertentu.

UNEP (2002) dan Sadler (2005) mengidentifikasi adanya 4 model pendekatan/kelembagaan KLHS, antara lain sebagai berikut:

- KLHS dengan kerangka dasar AMDAL (EIA Mainframe)

KLHS dalam model ini secara formal ditetapkan sebagai bagian dari peraturan perundangan AMDAL atau melalui peraturan lain namun memiliki prosedur yang terkain dengan AMDAL.

- KLHS sebagai kajian penilaian keberlanjutan lingkungan (Enviromental Appraisal Style) KLHS model ini menggunakan proses yang terpisah dengan system AMDAL. Prosedur dan pendekatannya telah dimodifikasi hingga memiliki karakteristik sebagai penilaian lingkungan.

- KLHS sebagai kajian terpadu atau penilaian keberlanjutan (Integrated Assessment/Sustainability Appraisal) 
KLHS ditempatkan sebagai bagian dari kajian yang lebih luas untuk menilai atau menganalisis dampak sosial, ekonomi, dan lingkungan hidup secara terpadu. Banyak pihak menempatkan model ini bukan sebagai KLHS melainkan Kajian Terpadu untuk Jaminan Keberlanjutan (ISA)

- KLHS sebagai pendekatan untuk pengelolaan berkelanjutan sumberdaya alam (Sustainable Resource Management)

KLHS diaplikasikan dalam kerangka pembangunan berkelanjutan dan dilaksanakan sebagai bagian tak terpisahkan dari hierarki system perencanaan penggunaan lahan dan sumberdaya alam serta sebagai bagian strategi spesifik pengelolaan sumberdaya alam.

Mendasarkan pada perkembangan pendekatan di atas, KLH (2007) menilai untuk Indonesia pendekatan yang tepat haruslah kontekstual disesuaikan dengan:

a. Kondisi sumberdaya alam dan lingkungan hidup yang menjadi fokus kajian,

b. Lingkup dan karakter KRP pemerintah pusat, provinsi, Kabupaten/Kota yang akan ditelaah,

c. Kapasitas institusi dan SDM aparatur pemerintah,

d. Kemauan politik (political will) yang kuat untuk menghasilkan KRP yang lebih berkualitas.

KLHS dapat disusun melalui banyak cara dan dapat mengadopsi multi-bentuk (form) bahkan namaserta memberi penilaian atas keputusan strategis yang akan diambil. Pertanyaan umum harus dijawab di setiap tipe aplikasi KLHS yang dipilih (CEAA 2004 dalam Sadler 2005) antara lain:

a. Apa manfaat (outcomes) langsung dan tidak langsung dari usulan KRP?

b. Bagaimana dan sejauh mana timbul interaksi antara manfaat KRP dengan lingkungan hidup?

c. Apa lingkup dan karakter interaksi tersebut? Apakah interaksi tersebut akan mengakibatkan timbulnya kerugian atau meningkatkan kualitas lingkungan hidup?

d. Dapatkah pengaruh negatif terhadap lingkungan hidup diatasi atau dimitigasi?

e. Bila seluruh upaya pengendalian atau mitigasi diintegrasikan ke dalam KRP, lantas secara umum apakah masih timbul pengaruh dari rencana KRP terhadap lingkungan hidup?

Asdak (dalam KLH, 2007) merangkum dari berbagai sumber di belahan dunia tentang kerangka kerja dan metode KLHS sebagaimana tergambarkan pada Gambar 2. 


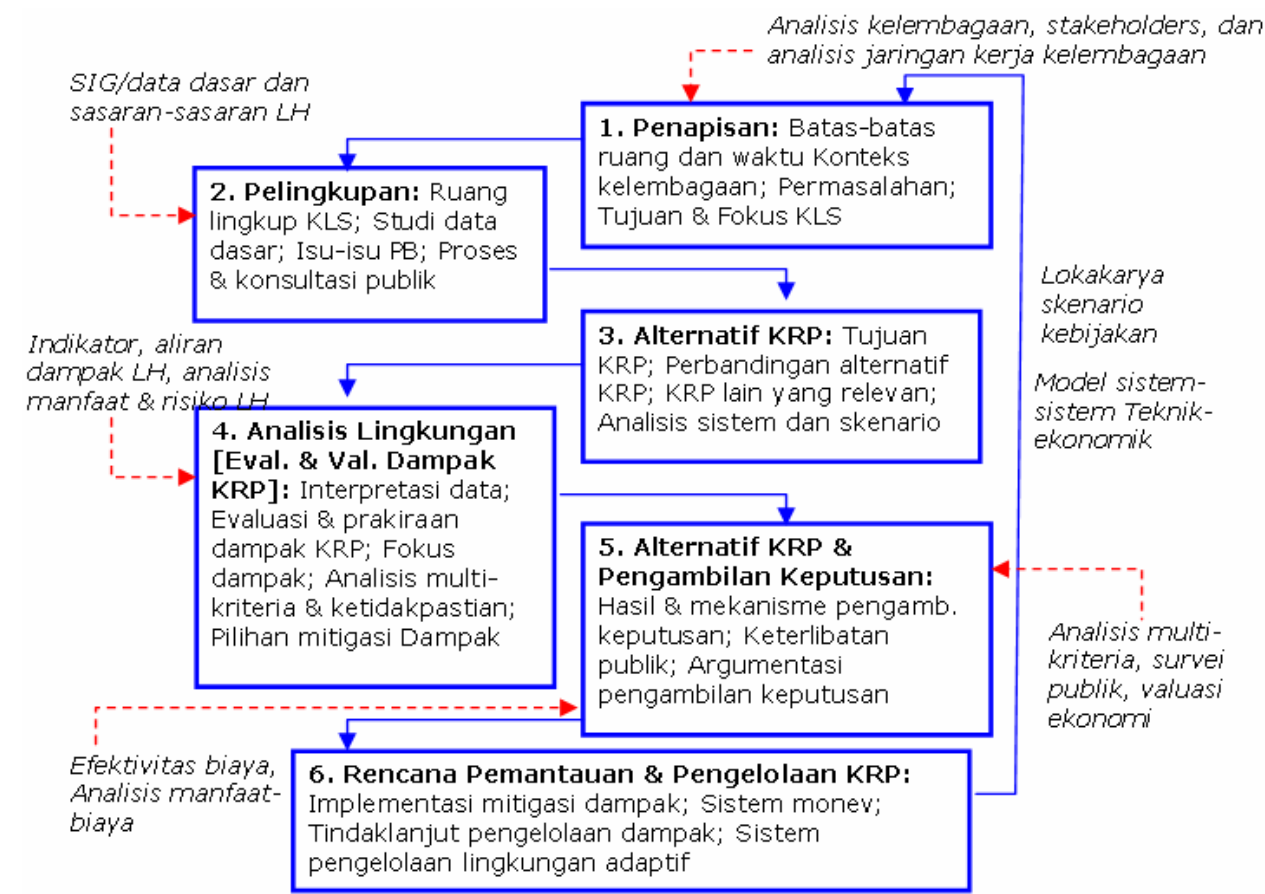

Gambar 2. Kerangka Kerja dan Metode KLHS (Asdak, dalam KLH, 2007)

KLHS merupakan konsep yang luas dan terbuka untuk berbagai variasi. Menurut KLH (2007), sejauh ini ada 6 tipe aplikasi KLHS, yaitu:

1. Integrasi KLHS dalam perencanaan ruang/regional

2. Integrasi KLHS dalam Rencana Pembangunan Jangka Panjang dan Jangka Menengah Daerah

3. Integrasi KLHS dalam penapisan Rencana Pembangunan Jangka Panjang dan Menengah Nasional

4. KLHS program perkotaan

5. KLHS sektor

6. KLHS kebijakan

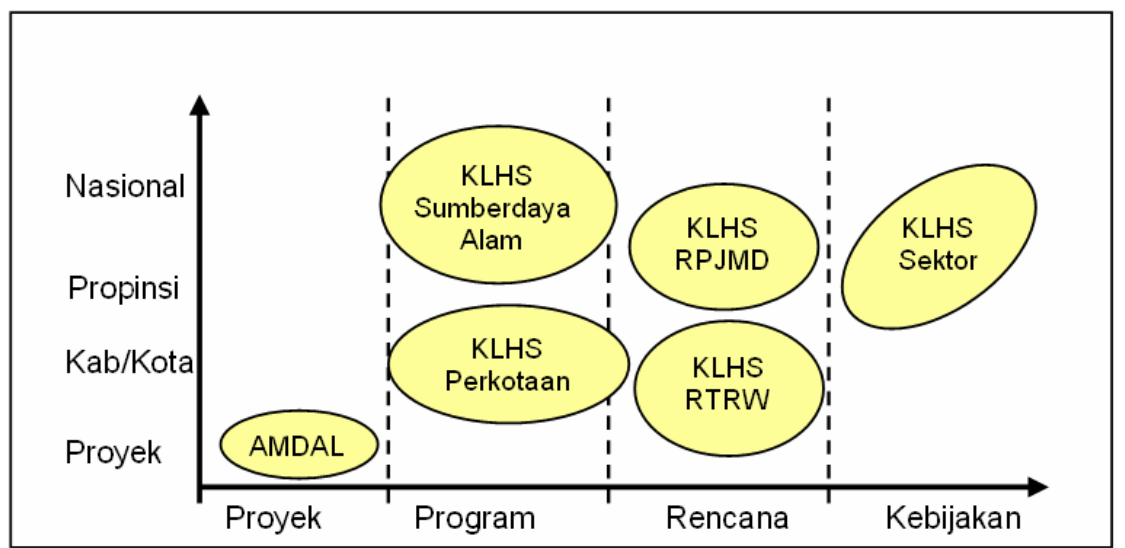

Gambar 3. Pijakan KLHS menurut dimensi waktu dan ruang (KLH, 2007) 
Aplikasi KLHS di Indonesia terentang dari lokal hingga nasional dan mencakup kebijakan, rencana, dan program. Aplikasi KLHS dilaksanakan di sepanjang proses KRP. Pada level kebijakan dapat diaplikasikan KLHS Kebijakan, pada level rencana dan program dapat berupa KLHS Regional (termasuk tata ruang), KLHS Program, dan KLHS Sektor. KLHS tidak berpretensi atau diarahkan untuk membuat sistem kelembagaan dan prosedur yang baru dan terpisah. KLHS lebih diarahkan untuk menjamin bahwa seperangkat prinsip dan nilai dasar KLHS diaplikasi ke dalam sistem yang sudah ada agar efektivitaf sistem tersebut meningkat. Dengan demikian, KLHS menjadi proses yang adaptif dan kontinu dengan fokus utama tata pengaturan (governance) dan penguatan kelembagaan, tidak sekedar pendekatan teknis, linier, dan sederhana sebagaimana AMDAL (OECD, 2006). KLH (2007) menilai untuk Indonesia pendekatan yang tepat haruslah kontekstual disesuaikan dengan:

- Kondisi sumberdaya alam dan lingkungan hidup yang menjadi fokus kajian,

- Lingkup dan karakter KRP pemerintah pusat, provinsi, Kabupaten/Kota yang akan ditelaah,

- Kapasitas institusi dan SDM aparatur pemerintah,

- Kemauan politik (political will) yang kuat untuk menghasilkan KRP yang lebih berkualitas.

\section{Aspek Legal KLHS di Indonesia}

Secara formal, landasan implementasi KLHS tercantum dalam Undang-undang No. 32 Tahun 2009 tentang Perlindungan dan Pengelolaan Lingkungan Hidup. Pasal 15 ayat 1 menegaskan "Pemerintah dan pemerintah daerah wajib membuat KLHS untuk memastikan bahwa prinsip pembangunan berkelanjutan telah menjadi dasar dan terintegrasi dalam pembangunan suatu wilayah dan/atau kebijakan, rencana, dan/atau program”. Pedoman penyusunan KLHS sudah diatur sebelum undang-undang tersebut disahkan melalui Peraturan Menteri Negara Lingkungan Hidup No. 27 Tahun 2009 tentang Pedoman Pelaksanaan KLHS.

\section{Belajar Aplikasi KLHS: Studi Kasus di Kartamantul, DIY}

Sebagai instrumen baru, belum banyak pemerintah daerah yang sudah menyusun KLHS. Salah satu daerah yang sudah memiliki dokumen KLHS adalah Provinsi DIY. Penyusunan KLHS di DIY diinisiasi dan selanjutnya dikoordinasikan oleh Badan Lingkungan Hidup (BLH). BLH DIY merencanakan KLHS dibagi untuk tiga kawasan berdasarkan homogenitas sifat fisik dan keterkaitan isu. Ketiga kawasan tersebut adalah Kartamantul dengan isu sumberdaya air, Gunungkidul dengan isu pengelolaan kawasan karst, serta Kulonprogo dengan isu bencana longsor. Salah satu KLHS yang sudah disusun adalah KLHS untuk Kartamantul, dimana Penulis juga terlibat dalam penyusunannya. 
KLHS Kartamantul dengan fokus pada konservasi sumberdaya air didasari pada kenyataan perkembangan wilayah Sleman sbagai kawasan penyangga sudah mengkhawatirkan dari sisi konservasi. Perubahan tata guna lahan cukup tinggi dan cenderung meningkat. Perubahan tertinggi adalah konversi dari lahan pertanian ke lahan terbangun. Perubahan tersebut sebagian besar terjadi untuk memenuhi berbagai kebutuhan seperti untuk permukiman, pendidikan, wisata dan tempat peristirahatan. Pada akhirnya perubahan tersebut telah mengurangi fungsi konservasi. Di sisi lain, wilayah tengah yaitu Kota Yogyakarta merupakan pusat perekonomian berupa perdagangan, jasa, dan industri dan menjadi tempat tujuan bagi warga Kabupaten Sleman (kawasan hulu) dan warga Kabupaten Bantul (kawasan hilir) untuk mencari rejeki. Dengan demikian terjadi hubungan timbal balik yang saling membutuhkan antara kawasan utara (hulu), tengah dan selatan (hilir).

Sebagaimana paparan di atas permasalahan lingkungan hidup paling krusial untuk Kabupaten Sleman, Kabupaten Bantul dan Kota Yogyakarta adalah sektor sumberdaya air. Secara garis besar dibutuhkan kebijakan komprehensif dan holistik untuk pengelolaan sumberdaya air di ketiga wilayah tersebut. Oleh karena itu, KLHS ini akan berfokus pada aspek kebijakan pengelolaan sumberdaya air atau dapat dikatakan KLHS ini termasuk tipe kombinasi sektoralkebijakan.

Hasil KLHS telah mengidentifikasi banyak isu spesifik terkait sumberdaya air, baik dari aspek lingkungan fisik, kebijakan dan kelembagaan, tata ruang, ekonomi, dan sosial kependudukan. Kompleksitas isu tersebut mencakup lintas wilayah, lintas sektor, dan lintas kelembagaan. Untuk mengurai atau mencari benang merah dalam rangka menentukan solusi permasalahan, diperlukan langkah yang sifatnya prioritatif dan memiliki cakupan komprehensif dan holistik. Langkah tersebut merupakan representasi dari pelingkupan isu-isu yang ada. Pelingkupan isu yang dilakukan diarahkan pada bagaimana kebijakan yang seharusnya diputuskan untuk meminimalisasi isu utama tersebut. Pelingkupan isu sumberdaya air di Kabupaten Sleman, Kota Yogyakarta, dan Kabupaten Bantul antara lain adalah:

a. Konversi lahan pertanian ke lahan terbangun

b. Kurang optimalnya penataan dan pengendalian ruang

c. Belum ada kebijakan khusus untuk pengelolaan sumberdaya air Kabupaten Sleman, Kota Yogyakarta, dan Kabupaten Bantul

d. Kurangnya sarana peresapan air hujan

e. Kurangnya monitoring pencemaran airtanah dan air sungai

f. Kesadaran sosial dan budaya terhadap lingkungan kurang dan belum tergerak masif 
Alternatif kebijakan yang direkomendasikan untuk pengelolaan lingkungan dan sumberdaya air di Kabupaten Sleman, Kota Yogyakarta, dan Kabupaten Bantul adalah sebagai berikut:

1. Kebijakan koordinasi tata ruang

2. Kebijakan pengendalian pemanfaatan ruang

3. Kebijakan pengembangan sarana peresapan atau penangkapan air hujan

4. Kebijakan pengendalian pencemaran air

5. Kebijakan partisipasi sosial budaya

Kebijakan-kebijakan di atas perlu dirincikan, baik substansi, mekanisme, dan siapa yang bertanggungjawab. Kajian mendalam perlu dilakukan, seperti dalam valuasi ekonomi dan penentuan prioritas kebijakan dari multi kriteria yang ada. Kebijakan-kebijakan tersebut tidak harus berdiri sendiri dan merupakan produk baru. Akan lebih efektif jika bersifat mengevaluasi atau melengkapi yang sudah ada serta dapat tercakup dalam beberapa kebijakan saja. Yang perlu diperhatikan lagi adalah realistis dan optimal tanpa mengurangi hal yang ideal. Siapa, apa, dan bagaimana merupakan kunci manajerial kebijakan tersebut. Hal ini merupakan rambu-rambu atau pijakan bagi kelanjutan pelaksanaan KLHS agar tetap fokus dan berkesinambungan. Kunci penting lainnya adalah sistem pengelolaan yang adaptif terhadap dinamika, sehingga setiap ada perubahan tidak membutuhkan kajian yang lama lagi, melainkan tinggal updating data dan koordinasi untuk penyikapan kebijakan. Dalam hal instansi pelaksana dapat diformulasikan tugas dan kewenangan utama instansi pemerintah untuk setiap tingkatan, seperti yang ditunjukkan pada Tabel 1.

Tabel 1. Arahan Fungsi dan Kewenangan Utama Instansi Pemerintah terkait Pengelolaan Sumberdaya air di Provinsi DIY

\begin{tabular}{|c|c|c|c|c|c|}
\hline \multirow[t]{2}{*}{ INSTANSI } & \multicolumn{4}{|c|}{$\begin{array}{c}\text { FUNGSI DAN KEWENANGAN } \\
\text { UTAMA }\end{array}$} & \multirow[t]{2}{*}{ KET } \\
\hline & 1 & 2 & 3 & 4 & \\
\hline \multicolumn{6}{|c|}{ Pusat } \\
\hline BAPPENAS & & & & & \multirow{3}{*}{$\begin{array}{l}\text { Jika terjadi kasus tertentu memberi bantuan } \\
\text { teknis atau pendanaan }\end{array}$} \\
\hline BLH & & & & & \\
\hline Departemen & & & & & \\
\hline \multicolumn{6}{|c|}{ Provinsi } \\
\hline \multicolumn{6}{|l|}{ BAPEDA } \\
\hline \multicolumn{6}{|l|}{ BLH } \\
\hline \multirow{2}{*}{\multicolumn{6}{|c|}{ Dinas Kimpraswil }} \\
\hline & & & & & \\
\hline \multicolumn{6}{|l|}{ Dinas terkait } \\
\hline \multicolumn{6}{|c|}{ Kabupaten/Kota } \\
\hline \multirow{2}{*}{\multicolumn{6}{|c|}{$\begin{array}{l}\text { BAPEDA } \\
\text { BLH/KAPEDAL }\end{array}$}} \\
\hline & & & & & \\
\hline \multicolumn{6}{|l|}{ Dinas Kimpraswil/PU } \\
\hline \multicolumn{6}{|l|}{ Dinas Kehutanan } \\
\hline \multicolumn{6}{|l|}{ Dinas terkait } \\
\hline \multicolumn{6}{|l|}{ Kecamatan } \\
\hline Desa & & & & & \\
\hline
\end{tabular}

Sumber: BLH DIY (2009)

Ket: 1 = Koordinatif, $2=$ Perencanaan, $3=$ Pelaksanaan, $4=$ Pengendalian (monitoring dan evaluasi) 
Hasil akhir dalam KLHS adalah bagaimana pengelolaan dan pemantauannya. KLHS merekomendasikan pengelolaan Kartamantul kaitannya dengan konservasi airtanah. Kawasan Kabupaten Sleman, Kota Yogyakarta dan Kabupaten Bantul dapat dibagi dalam 3 (tiga) kriteria kawasan konservasi resapan air yang wajib untuk dipertahankan dan ditingkatkan (Gambar 4) yaitu:

1. Kawasan Sangat Intensif

Merupakan kawasan konservasi air tanah sekaligus kawasan lindung untuk resapan air dimana perubahan lahan dari non terbangun menjadi terbangun sebaiknya tidak dilakukan lagi

2. Kawasan Intensif

Merupakan kawasan konservasi air tanah sekaligus kawasan budidaya pertanian lahan basah dan kering dimana untuk konservasi air tanahnya dilakukan dengan sangat membatasi perubahan lahan dari non terbangun menjadi terbangun dan diarahkan untuk pengembangannya secara vertikal.

3. Kawasan Restorasi

Merupakan kawasan konservasi air tanah sekaligus sebagai kawasan pengembangan lahan terbangun, karena fokusnya pada pengembangan lahan terbangun maka koservasi air tanah yang dilakukan di kawasan ini lebih banyak bersifat mekanis seperti biopori, sumur resapan dan teknologi lain yang bisa dilakukan untuk infiltrasi air tanah.

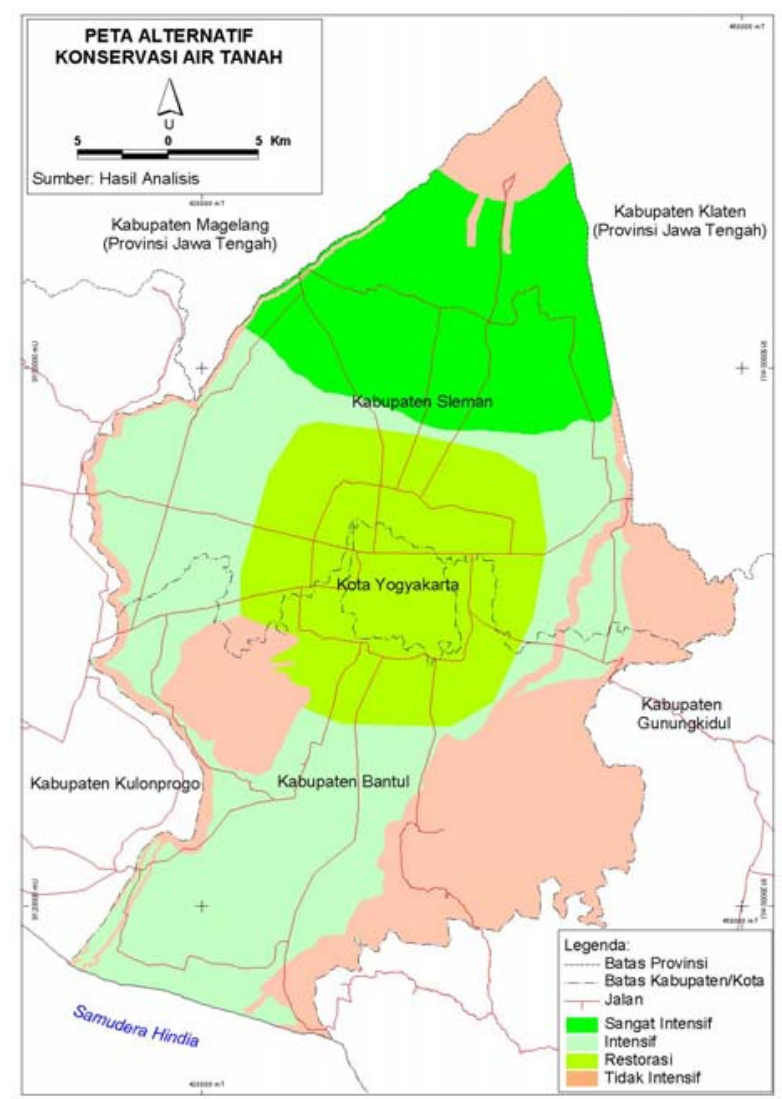

Gambar 4. Peta Alternatif Konservasi Airtanah 
Ancaman terhadap konservasi airtanah paling besar adalah konversi lahan yang tinggi. Oleh karena itu perlu prioritas pengendalian pemanfaatan ruang dalam rangka pengendalian laju konversi lahan. Pedoman pengendalian pemanfaatan ruang dan pembangunan adalah sebagai berikut:

1) Pedoman pengendalian pemanfaatan ruang didasarkan pada arahan-arahan yang tercantum dalam RTRW Provinsi dan Kabupaten/Kota, RTRK, RDTRK, dan RTBL;

2) Pengendalian pemanfaatan ruang meliputi sistem kegiatan, pemanfaatan ruang publik dan privat, ketentuan teknis bangunan, berbagai sektor kegiatan, sistem prasarana wilayah serta fasilitas dan utilitas kawasan;

3) Pengendalian pemanfaatan ruang dilaksanakan melalui kegiatan perijinan, pengawasan dan penertiban terhadap pemanfaatan ruang.

4) Apabila mekanisme pelaksanaan pemanfaatan ruang dan pembangunan tidak memenuhi ketentuan yang ditetapkan maka akan dilakukan penertiban dengan (1) pencabutan ijin, atau (2) pembongkaran dan atau (3) pengenaan denda progresif/ disintensif.

Mendasarkan pertimbangan sebelumnya, diperlukan kebijakan daerah yang secara spesifik berisi upaya pengelolaan sumberdaya air di Kabupaten Sleman, Kota Yogyakarta, dan Kabupaten Bantul. Selama ini kebijakan utama sudah ada, yaitu Rencana Tata Ruang Wilayah (RTRW). Konsep RTRW secara umum bisa megakomodasi kebutuhan pengaturan pemanfaatan dan pengendalian pemanfaatan ruang serta pengelolaan kawasan konservasi sumberdaya air. Oleh karena itu terdapat dua alternatif yang dapat dipertimbangkan, yaitu:

1. Peraturan mensejajarkan kebutuhan upaya pemanfaatan dan pengendalian pemanfaatan ruang. Peraturan yang dapat disusun adalah Peraturan Gubernur Tentang Pemanfaatan dan Pengendalian Pemanfaatan Ruang. Pada tahap berikutnya adalah menyiapkan serial Peraturan Gubernur tentang Pemanfaatan dan Pengendalian Pemanfaatan Ruang. Artinya tidak hanya satu tetapi ada beberapa peraturan yang dibutuhkan. Misalnya dapat disiapkan seri Peraturan Gubernur tentang:

a. Petunjuk Pelaksanaan Pengaturan Pemanfaatan dan Pengendalian Pemanfaatan Ruang

b. Pengorganisasian Pengaturan Pemanfaatan dan Pengendalian Pemanfaatan Ruang

c. Insentif dan Disinsetif dalam Pemanfaatan dan Pengendalian Pemanfaatan Ruang

d. Partisipasi Pemanfaatan dan Pengendalian Pemanfaatan Ruang

e. Pembiayaan Pemanfaatan dan Pengendalian Pemanfaatan Ruang

f. Pengelolaan Kawasan Lindung

g. Pengelolaan Kawasan Budidaya

h. dan sebagainya sesuai dengan kebutuhan dan perkembangan 
2. Peraturan yang mengatur pengelolaan kawasan lindung merupakan penjabaran dari peraturan pemanfaatan dan pengendalian pemanfaatan ruang. Pengelolaan kawasan lindung diatur dengan Peraturan Gubernur. Pada tahap berikutnya adalah disiapkan serial Peraturan Gubernur tentang Petunjuk Pelaksanaan Pengelolaan Kawasan Lindung. Artinya tidak hanya satu tetapi ada beberapa peraturan yang dibutuhkan. Misalnya dapat disiapkan seri Peraturan Gubernur tentang:

a. Pengorganisasian Pengelolaan Kawasan Lindung

b. Penetapan Kawasan Lindung Diluar Kawasan Hutan

c. Penetapan Kawasan Lindung Lainnya

d. Insentif dan Disinsetif dalam Pengelolaan Kawasan Lindung

e. Partisipasi Pengelolaan Kawasan Lindung

f. Pembiayaan Pengelolaan Kawasan Lindung

g. dan sebagainya sesuai dengan kebutuhan dan perkembangan

Selain kebijakan juga perlu disiapkan kelembagaan/institusinya. Institusi pengelolaan tata ruang dan kawasan konservasi di Kartamantul dapat dikoordinasikan pada sebuah forum atau lembaga. Beberapa alternatif lembaga atau forum tersebut diantaranya:

1. Mengembangkan yang sudah ada, misalnya :

- Badan Koordinasi Penataan Ruang Daerah (BKPRD) Provinsi DIY. Karena kebutuhan dan kekhasannya, Kabupaten Sleman, Kota Yogyakarta, dan Kabupaten Bantul dapat menjadai Sub Bagian tersendiri. Konsekuensinya lembaga ini diperkuat Tupoksi-nya agar lebih optimal

- Sekretariat Bersama (Sekber) Kabupaten Sleman, Kota Yogyakarta, dan Kabupaten Bantul (Kartamantul). Konsekuensinya lembaga ini harus diperluas kewenangan dan bidang garapnya.

2. Membuat forum/lembaga koordinasi baru

Selain instansi pelaksana, diperlukan instansi yang melakukan monitoring dan evaluasi secara definitif. Selama ini fungsi pengawasan pengendalian pembangunan atau tata ruang sangat minim terlaksana. Beberapa alternatif yang dapat melakukannya adalah:

1. Menjadi bagian dalam instansi pelaksana pengelolaan, misalnya menjadi bidang khusus pada BKPRD atau Sekber Kartamantul.

2. Terpisah dengan instansi pelaksana pengelolaan, misal: 
- Meletakkan kewenangan pada Inspektorat Daerah, dengan memperluas Tupoksinya menjadi semacam Inspektorat Pembangunan Daerah

- Mengoptimalkan BAPEDA dengan bidang khusus yang lebih optimal

- Membentuk lembaga pengawasan dan pengendalian baru

\section{Daftar Pustaka}

BLH DIY. (2009). Kajian Lingkungan Hidup Strategis Kabupaten Sleman, Kota Yogyakarta, dan Kabupaten Bantul, Laporan Akhir, Yogyakarta: BLH DIY.

DEAT dan CSIR. (2000). Strategic Environmental Assessment in South Africa: Guidline Document, Department of Environmental Affairs and Tourism, Pretoria.

DEAT. (2004). Strategic Environmental Assessment, Integrated Environmental Management Series, Pretoria.

IAIA. (2002). Strategic Environmental Assessment: Performance Criteria. Special Publication Series No. 1, The International Association of Impact Assessment (www.iaia.org/publications)

KLH. (2007). Buku Pegangan Kajian Lingkungan Hidup Strategis, Kementerian Negara Lingkungan Hidup, Jakarta.

OECD. (2006). Appliying Strategic Environmental Impact Assessment: Good Practice Guidance for Development Cooperation. OECD Publishing.

Partidario, M.R. (2000). Elements of SEA framework -improving the added- value of SEA, Environmental Impact Assessment Review 20.

Sadler and Brook. (1998). Strategic Environmental Appraisal, Department of the Environment, Transport and the Regions, London, UK.

Sadler and Verheem. (1996). Strategic Environmental Assessment : Status, Challenges, And Future Directions. Report no. 53. Ministry Of Housing, Physical Planning and Environment, The Hague.

Sadler. (2005). Strategic Environmental Assessment at the Policy Level : Recent Progress, Curent Status, and Future Prospect. Editor. Ministry of The Environment, Czech Republic, Praha.

Suratmo. (2004). Analisis Mengenai Dampak Lingkungan, Gadjah Mada University Press, Yogyakarta.

Therievel, et al. (1992). Strategic Environmental Assessment, Earthscan, London.

UNEP. (2002). EIA Training Resource Manual, United Nation Environmental Program. 